CENTRE for ECONOMIC

$P$ E R F O R M A N C E

CEP Discussion Paper No 727

June 2006

\title{
Trade and Growth with Heterogeneous Firms
}

Richard E. Baldwin and Frédéric Robert-Nicoud

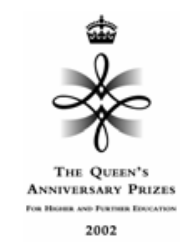




\begin{abstract}
This paper explores the impact of trade on growth when firms are heterogeneous. We find that greater openness produces anti-and pro-growth effects. The Melitz-model selection effects raises the expected cost of introducing a new variety and this tends to slow the rate of new-variety introduction and hence growth. The pro-growth effect stems from the impact that freer trade has on the marginal cost of innovating. The balance of the two effects is ambiguous with the sign depending upon the exact nature of the innovation technology and its connection to international trade in goods and ideas. We consider five special cases (these include the Grossman-Helpman, the Coe- Helpman and Rivera-Batiz-Romer models) two of which suggest that trade harms growth; the others predicting the opposite.
\end{abstract}

JEL Classifications: H32, P16

Keywords: trade and endogenous growth, heterogeneous firms, dynamic versus static efficiency.

This paper was produced as part of the Centre's Globalisation Programme. The Centre for Economic Performance is financed by the Economic and Social Research Council.

\title{
Acknowledgements
}

We are grateful for comments and observations from Thomas Chaney, Jan Haaland, Gene Grossman, Elhanan Helpman, Wolfgang Keller, Tommaso Mancini, Marc Melitz, Virginia Di Nino, Toshi Okubo and seminar participants at Hitotsubashi University, LSE, University of Barcelona and at the 2005 CEPR European Workshop on International Trade. Two referees and the JIE editor Jon Eaton provided excellence advice which much improved the paper.

Richard Baldwin is Professor of International Economics at the Graduate Institute of International Studies, Geneva. Frédéric Robert-Nicoud is an Associate with the Globalisation programme at the Centre for Economic Performance and a Lecturer in the Department of Geography and Environment, London School of Economics.

Published by

Centre for Economic Performance

London School of Economics and Political Science

Houghton Street

London WC2A $2 \mathrm{AE}$

All rights reserved. No part of this publication may be reproduced, stored in a retrieval system or transmitted in any form or by any means without the prior permission in writing of the publisher nor be issued to the public or circulated in any form other than that in which it is published.

Requests for permission to reproduce any article or part of the Working Paper should be sent to the editor at the above address.

(C) R. E. Baldwin and F. Robert-Nicoud, submitted 2006

ISBN 0753020238 


\title{
Trade and growth with heterogeneous firms
}

\author{
Richard E. Baldwin and Frédéric Robert-Nicoud*
}

\section{INTRODUCTION}

Until the 1980s, trade theory assumed away intra-industry trade for convenience, but empirical evidence revealed that much of world trade was exactly of the assumed-away kind (Grubel and Lloyd 1975). In response, the so-called new trade theory (Helpman and Krugman 1985) incorporated imperfect competition and increasing returns to account for intra-industry trade. The modelling choices made by new trade theorists assumed away, again for convenience, differences among firms. Recent empirical evidence, however, shows that differences among firms are crucial to understanding world trade. For example, firm differences within sectors may be more pronounced than differences between sector averages, and most firms - even in traded-goods sectors - do not export at all (Bernard and Jensen 1995, 1999a,b, 2001; Clerides, Lach and Tybout

\footnotetext{
* Submitted to JIE February 2005. This paper replaces a July 2004 draft written as a comment on Melitz (2003) for Econometrica. The (rejecting) referees' critiques were that our 9 page comment was not fair to the literature, ignored welfare and omitted intuition. This draft redresses these faults and extends the analysis in several directions.
} 
1998, Aw, Chung, and Roberts 2000, Eaton, Kortum, and Kramarz 2004; see Tybout 2003 for a survey). In response, what might be called the 'new new' trade theory incorporated firm-level heterogeneity to account for the many of the new firm-level facts. The main theoretical papers in this rapidly expanding literature are Bernard, Eaton, Jensen and Kortum (2003), Melitz (2003), Helpman, Melitz and Yeaple (2004), Bernard, Redding and Schott (2004), Bernard, Eaton, Jensen, and Schott (2003), Melitz and Ottaviano (2003), Yeaple (2005), Luttmer (2005a, b) and Chaney (2005).

Our paper studies the growth effects of greater openness by embedding a heterogeneous-firms trade model in a series of product-innovation endogenous growth models (Grossman and Helpman 1989, 1991, Romer 1986, 1990, Rivera-Batiz and Romer 1991a, b, Coe and Helpman 1995, Dinopoulos and Segerstrom 1999a, b, Keller 2004). We show that openness may either slow or speed growth depending upon the impact of openness on the marginal cost of innovating. Since growth is too slow from a welfare perspective in our model (as usual in product-innovation models), there can be a tension between the dynamic and static welfare effects when greater openness slows growth. We show, however, that the overall welfare impact is unambiguously positive.

To make these points as simply as possible, we work with a new-new trade model related to Helpman, Melitz and Yeaple (2004) and a 'portmanteau' product-innovation growth model that includes as special cases Grossman and Helpman's product innovation model (Grossman and Helpman 1991 chapter 4), Rivera-Batiz and Romer's 'lab-quipement' model, as well as three other models. This task is made easier by the fact that these models are based on the well-known Helpman-Krugman trade model. Indeed, it is insightful to think of our model as the Krugman (1980) model with three important additions. First, we allow for knowledge spillovers in varietycreation so that the cost of developing a new variety falls at the same pace as the value of introducing a new variety. This eliminates the mass of varieties from the equilibrium conditions with the growth rate of the mass of varieties taking its place as a key equilibrating variable; it also allows us to endogenise the growth rate. Second, we add heterogeneity in firms' marginal production costs, using the Hopenhayn-Melitz variety generation/selection set-up where firms are randomly assigned a marginal cost after having paid a start-up cost. Third, we add sunk marketentry cost as in the 'hysteresis and trade' literature (Baldwin 1988, Baldwin and Krugman 1989, Dixit 1989). The sunk costs of establishing a marketing 'beachhead' interact with the heterogeneous marginal costs to produce two types of active firms - firms that sell only locally and firms that export as well as sell locally. 
The paper is organised in five sections after the introduction. The next two present the model (section 2) and work out the long-run growth path (section 3). The subsequent two sections work out the growth effects of greater openness (Section 4) and the welfare implications (Section 5). Section 6 presents our concluding remarks.

\section{A HETEROGENEOUS FIRMS TRADE MODEL WITH GROWTH}

The foundation of our model is the well-known Helpman-Krugman monopolistic competition model. We work with two identical nations, a single primary factor L, and a single Dixit-Stiglitz goods sector ('manufactures') with differentiated varieties that consumers view as symmetric. Competition takes the form of Dixit-Stiglitz monopolistic competition among firms facing iceberg trade costs. Each manufacturing firm's production cost function is linear, involving a sunk, varietydevelopment cost (we denote this 'start-up cost' as $F_{I}$ where I is a mnemonic for 'innovation') and a constant marginal production cost (we denote the unit labour input coefficient as ' $a$ ').

Manufacturing firms are assumed to be heterogeneous with respect to their marginal production cost. A typical firm's ' $a$ ' is drawn from a density function $G[a]$ whose support is $0 \leq a \leq a_{0}$. The firm learns its ' $a$ ' after it has paid the start-up cost, $\mathrm{F}_{\mathrm{I}}$.

Selling a new variety in a particular market also requires the firm to pay a sunk cost that reflects the cost of adapting the variety to market-specific standards, regulations and norms. These costs which we refer to as 'beachhead' costs - may differ for locally produced varieties and imported varieties. The cost of establishing a 'beachhead' for locally made products is $F_{D}$ ( $D$ is a mnemonic for domestic) and $\mathrm{F}_{\mathrm{X}}$ for imported varieties ( $\mathrm{X}$ is a mnemonic for exports).

The three fixed costs - the start-up cost $F_{I}$ and the two beachhead costs $F_{D}$ and $F_{X}$ - involve units of 'knowledge'. The start-up cost requires $\kappa_{\mathrm{I}}$ units of knowledge, while adapting it to local and export market conditions requires $\kappa_{\mathrm{D}}$ units and $\kappa_{\mathrm{X}}$ units of knowledge, respectively. Thus:

$$
F_{I}=\kappa_{I} P_{K}, \quad F_{D}=\kappa_{D} P_{K}, \quad F_{X}=\kappa_{X} P_{K}
$$

where $\mathrm{P}_{\mathrm{K}}$ is the price of a unit of knowledge ( $\mathrm{K}$ for knowledge), and the $\kappa$ 's are expressed in units of knowledge. Knowledge is created by a perfectly competitive 'innovation sector' (I-sector for short) and sold to potential entrants in the manufacturing sector. ${ }^{1}$ The I-sector produces knowledge using labour; its technology can be written implicitly as:

\footnotetext{
${ }^{1}$ The Hopenhayn-Melitz approach folds variety development into manufacturing, but innovation is the engine of growth in our model, so we separate innovation and manufacturing by introducing an explicit innovation sector.
} 


$$
Q_{K}=\frac{S}{P_{K}} ; \quad P_{K}=c[w, \vec{a}, n]
$$

where $\mathrm{Q}_{\mathrm{K}}$ is the flow of new knowledge (the I-sector's output), and $\mathrm{S}$ is total spending on new knowledge ( $\mathrm{S}$ is a mnemonic for savings since in equilibrium all savings goes to buy new knowledge). Competition ensures $\mathrm{P}_{\mathrm{K}}$ equals $c[w, \vec{a}, n]$ which is the I-sector's marginal cost function; its arguments are the price of labour w, the vector of all unit-input coefficients of manufactured varieties $\vec{a}$, and the number (mass) of these varieties, $\mathrm{n}$. This allows the cost of producing knowledge to be influenced by the cost of direct inputs (labour) as well as the general level of efficiency in the economy as captured by $\vec{a}$ and $\mathrm{n}$. The only restriction we impose at this point is that $\mathrm{c}[\cdot]$ is homogenous of degree minus one in $\mathrm{n}$ due to technological spillovers. This means that the cost of knowledge falls as the I-sector learns from the experience of having made ' $n$ ' varieties (as usual in endogenous growth models). We leave $\mathrm{c}[\cdot]$ implicit for the moment.

\section{THE EQUILIBRIUM}

This section works out the steady state growth rate and characterises the equilibrium distribution of firm-level productivity. We first work out the instantaneous equilibrium, i.e. the economy's equilibrium at a point on the long-run growth path taking the growth rate as given.

\subsection{Instantaneous equilibrium}

Entry decisions are the fulcrum of this model and there are two types: 1) the start-up decision, and 2) the two market-entry decisions. Although these are linked, we treat them in sequence.

A firm that has already sunk its start-up cost will enter a particular market if the benefit of doing so exceeds the cost. The benefit of entering a market depends upon the firm's anticipated sales and these, in turn, depend upon the firm's marginal selling cost relative to that of its competitors. Relying on the standard logic of fixed costs, we can already anticipate that only firms with sufficiently low marginal costs will enjoy market shares that are high enough to justify sinking the beachhead costs. Since there are two beachhead costs $\left(\mathrm{F}_{\mathrm{X}}\right.$ and $\left.\mathrm{F}_{\mathrm{D}}\right)$ there will be two thresholds, one for domestic sales, which we denote as $\mathrm{a}_{\mathrm{D}}$, and one for export sales, which we denote as $\mathrm{a}_{\mathrm{X}}$. These two thresholds define three types of firms. The most efficient firms, i.e. those with the lowest unit labour requirements $\left(a<a_{x}\right)$ sell locally and also export (we call these X-types, short for export firms). The least efficient firms $\left(a>a_{D}\right)$ do not produce (we call these N-types, short for nonproducers). Firms with intermediate efficiency $\left(\mathrm{a}_{\mathrm{X}}<\mathrm{a}<\mathrm{a}_{\mathrm{D}}\right)$ will produce but only sell locally (we call these D-types, short for domestic firms). 
To flesh out this intuition, we characterise the operating profit that firms would earn if they decided to enter a given market. Under Dixit-Stiglitz competition, firms find it optimal to charge a constant operating profit margin, $1 / \sigma$, where $\sigma>1$ is the constant elasticity of substitution among varieties. ${ }^{2}$ Thus the operating profit that a firm earns in a particular market equals the value of the firm's sales times $1 / \sigma$, where the value of its sales are its market-specific market-share times total spending in the market, E.

By symmetry, wages are equalised internationally, so taking labour as numeraire $(\mathrm{w}=1)$ and using well-known Dixit-Stiglitz results, firm-j's price in its local market is $a_{j} /(1-1 / \sigma)$. If it exports, its price in the export market is $\tau \mathrm{a}_{\mathrm{j}} /(1-1 / \sigma)$, where $\tau \geq 1$ represents the usual iceberg trade costs ( $\tau$ units must be shipped to sell one unit in the export market). Thus, a firm's market share as a function of its marginal selling cost is:

$$
s[m]=\left(\frac{1}{n}\right) \frac{m^{1-\sigma}}{\bar{m}} ; \quad \bar{m}=\int_{0}^{a_{D}} a^{1-\sigma} d G\left[a \mid a_{D}\right]+\phi \int_{0}^{a_{X}} a^{1-\sigma} d G\left[a \mid a_{D}\right] ; \quad 0 \leq \phi \equiv \tau^{1-\sigma} \leq 1
$$

where ' $m$ ' is the firm's marginal selling cost ('a' for local sales and $\tau$ a for export sales), ' $n$ ' is the mass of firms, $\bar{m}$ is the weighted average of firms' marginal selling costs in a particular market, and $G\left[a \mid a_{D}\right]$ is the conditional density function of the a's for producing firms, i.e. a $<\mathrm{a}_{\mathrm{D}}{ }^{3} \mathrm{~A}$ critical parameter in our paper is the level of trade freeness (phi-ness); $\phi$ ranges from zero when trade is perfectly closed $(\tau=\infty)$ to unity when trade is perfectly free $(\tau=1)$, thus trade gets freer as $\phi$ rises. Equation (3) is pivotal; five observations facilitate intuition and subsequent analysis: i) The ratio, $\mathrm{m}^{1-\sigma} / \bar{m}$, is a measure of the firm's market-specific competitiveness, i.e. its marginal selling cost relative to an average of its competitors' marginal selling costs; ii) A firm's market share exceeds $1 / \mathrm{n}$ to the extent its competitiveness is above average; iii) A firm's market share (and thus its operating profit) increases as its marginal cost falls, ceteris paribus; iv) The average marginal selling costs, $\bar{m}$, depends on the two cut-off marginal costs, $\mathrm{a}_{\mathrm{D}}$ and $\mathrm{a}_{\mathrm{X}}$, and the distribution $\mathrm{G}$; note that the geometric weights are negative $(1<\sigma)$ so higher marginal costs lower $\bar{m}$; v) As the mass of active firms ' $n$ ' grows (as it will along the steady state growth path), the market shares of all existing firms decline in tandem and at the rate at which $n$ grows.

Cut-off conditions. Given the sunk-ness of the beachhead costs, $F_{D}$ and $F_{X}$, the relevant benefit of market entry is the present value of the market-specific operating profit. Defining the discount

\footnotetext{
${ }^{2}$ See Guide to Calculations for details available on www.hei.unige.ch/ baldwin/
} 
rate as $\gamma$ and using (3), firm-j's benefit from entering its local and export market are, respectively, $\mathrm{s}\left[\mathrm{a}_{\mathrm{j}}\right] \mathrm{E} / \sigma \gamma$ and $\phi \mathrm{s}\left[\mathrm{a}_{\mathrm{j}}\right] \mathrm{E} / \sigma \gamma$, where $\mathrm{E}$ is total spending on manufactured goods in each (symmetric) market. The market-entry cut-off conditions are thus:

$$
s\left[a_{D}\right] \frac{E}{\sigma \gamma}=P_{K} \kappa_{D} ; \quad \phi s\left[a_{X}\right] \frac{E}{\sigma \gamma}=P_{K} \kappa_{X}
$$

where $a_{D}$ and $a_{X}$ are the cut-off marginal costs for entering the local market and the export market respectively ( $\mathrm{D}$ stands for domestic and $\mathrm{X}$ for export).

Free entry condition. A potential entrant to the manufacturing sector must pay $F_{I}$ to develop a new variety, learning the variety's associated ' $a$ ' only after sinking $F_{\mathrm{I}}$. The potential entrant then decides whether to invest in the further knowledge that is necessary to enter the local market and the export market. Potential entrants that draw N-type varieties $\left(a>a_{D}\right)$ abandoned their project. Those lucky enough to get $a<a_{D} \operatorname{sink} F_{D}$ and $F_{X}$, depending upon the revealed 'a'. Plainly, the value of the resulting variety depends on its ' $a$ '. Calculating these values is easy, but not necessary. A firm's start-up decision can be cast in terms of the expected present value of a 'winning' variety (winning in the sense that it is actually produced, i.e. is a D- or X-type). Because we focus on steady states, the ex ante likelihood of getting a winner with any particular 'a' is exactly the same as the actual distribution of a's for winners already in the market. In other words, the expected operating profit of a winner must exactly match the average operating profit earned in the market. This average is $\mathrm{E} / \sigma \mathrm{n}$ because total operating profit worldwide equals $2 \mathrm{E} / \sigma$ (due to the constancy of the Dixit-Stiglitz operating profit margin) and the worldwide mass of varieties is $2 \mathrm{n}$. Thus: ${ }^{4}$

$$
\text { Expected value of a 'winner' }=\frac{E}{\sigma n \gamma}
$$

Of course, innovators do not come up with a winner every try; only new varieties with $\mathrm{a}_{<\mathrm{D}}$ will be 'winners'. It is straightforward to calculate the expected fixed cost of getting a winner (i.e. developing a D or $\mathrm{X}$ type patent). The answer is:

$$
\bar{F} \equiv P_{K} \bar{\kappa} ; \quad \bar{\kappa} \equiv \kappa_{D}+\kappa_{X} \frac{G\left[a_{X}\right]}{G\left[a_{D}\right]}+\kappa_{I} \frac{1}{G\left[a_{D}\right]}
$$

\footnotetext{
${ }^{3}$ Since only varieties with a $<\mathrm{a}_{\mathrm{D}}$ are produced, $G\left[a \mid a_{D}\right]$ equals $\mathrm{G}[\mathrm{a}] / \mathrm{G}\left[\mathrm{a}_{\mathrm{D}}\right]$. See Melitz (2003) for a proof.

${ }^{4}$ This 'expected=observed' result marks the steady state in any model with a memory-less firm-birth and death process. Eaton and Kortum (2002) use a similar approach.
} 
Where $\bar{F}$ is the expected fixed cost, which depends upon the price of knowledge $\mathrm{P}_{\mathrm{K}}$ and the expected units of knowledge required to get a 'winner.' The first term in $\bar{\kappa}$ is the fixed cost for local sales - an expense that every winner incurs. The second term reflects the fact that a fraction of winners are $X$-types and so incur $\kappa_{X}$ as well; $G\left[a_{X}\right] / G\left[a_{D}\right]$ is the probability of being an X-type conditional on being a winner. The third right-hand term reflects the expected variety development cost, i.e. $\kappa_{\mathrm{I}}$ times the inverse probability of getting a winner on a random draw since, i.e. $1 / G\left[a_{D}\right]$ is the number of 'tries' needed to get a winner.

The expected pure profit from developing a new variety is $(\mathrm{E} / \sigma n \gamma-\bar{F})$. Free entry drives this to zero, so the free entry condition for variety introduction is: ${ }^{5}$

$$
\frac{E / \sigma}{n \gamma}=P_{K} \bar{\kappa}
$$

If we took the ratio of $(E / \sigma n \gamma)$ and $\mathrm{P}_{\mathrm{K}} \bar{\kappa}$, (6) would be Tobin's q=1 equation since E/ $\sigma \mathrm{n} \gamma$ is akin to the expected stock market value and $\mathrm{P}_{\mathrm{K}} \bar{\kappa}$ is the expected replacement cost. As we shall see, all growth effects of trade work through the replacement cost. ${ }^{6}$

Since c[·] from (2) is homogeneous of degree minus one in n, we can use an 'intensive form' of $\mathrm{P}_{\mathrm{K}}$, $\mathrm{p}_{\mathrm{K}} \equiv \mathrm{nP}_{\mathrm{K}}$. With this notation, the cut-off and free entry conditions, (4) and (6), are:

$$
\frac{a_{D}{ }^{1-\sigma} E}{\bar{m} \sigma \gamma}=p_{K} \kappa_{D}, \quad \frac{\phi a_{X}{ }^{1-\sigma} E}{\bar{m} \sigma \gamma}=p_{K} \kappa_{X}, \quad \frac{E}{\sigma \gamma}=p_{K} \bar{\kappa} ; \quad p_{K} \equiv n P_{K}=c[w, \vec{a}, 1]
$$

Observe that ' $n$ ' drops out of the three conditions (as it must if $\mathrm{n}$ is to continue rising forever on the growth path). In an endogenous growth model, the discount factor $\gamma$ - which varies with the growth rate - adjusts as 'n' would in a no-growth model.

\subsection{Saving, investment and growth}

To finish our characterisation of the growth path, we need to address two further issues: the equilibrium discount rate, and the utility maximising division of income between consumption and saving/investment. To this end, we work with simple intertemporal preferences, namely:

$$
U=\int_{0}^{\infty} e^{-\rho t} \ln D_{t} d t ; \quad D=\left(\int_{i \in \Theta} d_{i}^{1-1 / \sigma} d i\right)^{1 /(1-1 / \sigma)} ; \quad Y=E+S ; \quad Y=L+\frac{E}{\sigma}
$$

\footnotetext{
${ }^{5}$ See Guide to Calculations for details of the correspondence between ours and the Melitz (2003) approach.

${ }^{6}$ See the Guide to Calculations for details.
} 
where $\rho$ is the rate of pure time preference, D is the CES consumption composite, $\Theta$ is the (timevarying) set of consumed varieties, and $\mathrm{d}_{\mathrm{i}}$ is consumption of variety-i. Consumers divide income $\mathrm{Y}$ between current expenditure $\mathrm{E}$ and saving/investment $\mathrm{S}$, where $\mathrm{Y}$ equals labour income, L, plus all manufacturing operating profit $\mathrm{E} / \sigma$ (I-sector profit is zero). Utility optimisation implies a transversality condition and the Euler equation ${ }^{7}$ :

$$
\dot{E} / E=r-\rho
$$

where ' $r$ ' is the rate of return on saving/investment. Expenditure on goods E equals income less spending on new units of knowledge, S. Since there are zero pure profits in the I-sector, S equals the value of inputs, i.e. labour employed in the $\mathrm{I}$-sector, $\mathrm{L}_{\mathrm{I}}($ recall $\mathrm{w}=1)$. Thus $\mathrm{E}=\mathrm{L}+\mathrm{E} / \sigma-\mathrm{L}_{\mathrm{I}}$, so:

$$
E=\frac{L-L_{I}}{1-1 / \sigma} \quad \Leftrightarrow \quad L_{I}=L-E(1-1 / \sigma)
$$

Thus determining the utility-maximising path of expenditure $\mathrm{E}$ also pins down the savings/investment path $\mathrm{S}=\mathrm{L}_{\mathrm{I}}$. The implied growth rate of ' $\mathrm{n}$ ' given $\mathrm{L}_{\mathrm{I}}$ is:

$$
\dot{n}=\frac{Q_{K}}{\bar{\kappa}} \quad \Leftrightarrow \quad g=\frac{L_{I}}{p_{K} \bar{\kappa}} ; \quad g \equiv \frac{\dot{n}}{n}
$$

where the first and second expressions are related by (2), $S=\mathrm{L}_{\mathrm{I}}$ and $\mathrm{p}_{\mathrm{K}} \equiv \mathrm{P}_{\mathrm{K}} \mathrm{n}$; $\mathrm{g}$ is the growth rate of n. Note that a constant $L_{I}$ implies a constant growth in the mass of varieties $n$.

Solving for the time-path of $\mathbf{E}$. The economy can be described as a dynamic system consisting of two differential equations, the Euler equation (9) and the growth of varieties equation (11). To solve these for the steady state, we must specify the state variable. Although the steady state is unaffected by the choice of state variables, the ease of calculation depends greatly on this choice. Following Baldwin and Forslid (1991), we choose $\mathrm{L}_{\mathrm{I}}$ as the state variable. The fruit of this choice is immediately apparent. First, r $=\rho$ given expressions (9) and (10) and the fact that $\dot{L}_{I}=0$ by definition of steady state. ${ }^{8}$ Moreover, if $\mathrm{L}_{\mathrm{I}}$ stops evolving, (11) tells us that $\mathrm{g}$ is constant along the steady-state growth path. The discount rate, $\gamma$, is simple to calculate, e.g. the present value of a D-type's operating profit is:

$$
\int_{0}^{\infty}\left\{e^{-(\rho+g) t} a^{1-\sigma} E /\left(\sigma n_{0} \bar{m}\right)\right\} d t \quad a_{X} \leq a \leq a_{D}
$$

\footnotetext{
${ }^{7}$ See the Guide to Calculations for details.

${ }^{8}$ Note that this presumes the steady state exists and is stable in the relevant sense; see Guide to Calculations for details.
} 
Where $n_{0}$ is the initial $n$, and $\mathrm{e}^{-\rho t}$ reflects the fact that the consumer/owner requires a return of $r=\rho$ in order to forego the consumption necessary to finance the creation of a new variety, and the term $\mathrm{e}^{\mathrm{gt}}$ reflects the rate at which the new firm's market share (and thus operating profit) declines due to the expansion of competitors as per (3) and (11). Solving the integral, the present value is $a^{1-}$ ${ }^{\sigma} \mathrm{E} / \sigma \mathrm{n}_{0} \gamma \bar{m}$ where $\gamma=\rho+\mathrm{g}$. Intuitively, the gross discount rate $\gamma$ reflects pure time preference $\rho$ and the rate at which the typical variety's market share falls, namely g.

Summarising, expenditure E, savings/investment $\mathrm{S}=\mathrm{L}_{\mathrm{I}}$, the growth rate of varieties $\mathrm{g}$, and the discount rate $\gamma$ are time-invariant along the steady state growth path. The dynamic system therefore reduces to three equations - the two cut-off conditions and the free entry condition - with three unknowns, $g, a_{D}$ and $a_{X}$. The only thing left to find is the utility maximising level of E.

Using (10), (11), and the third expression in (7) yields the intuitive result that the utility-maximising E equals 'permanent income', i.e. the income from labour L plus the rental rate on the steady-state value of the nation's capital stock (which equals $\mathrm{p}_{\mathrm{K}} \overline{\bar{\kappa}}$ ): ${ }^{9}$

$$
E=L+\rho p_{K} \bar{\kappa}
$$

Using this and $\gamma=\rho+g$ in (7), the cutoff and free entry conditions are:

$$
\frac{a_{D}{ }^{1-\sigma}\left(L+\rho p_{K} \bar{\kappa}\right)}{\bar{m} \sigma(\rho+g)}=p_{K} \kappa_{D}, \quad \frac{\phi a_{X}{ }^{1-\sigma}\left(L+\rho p_{K} \bar{\kappa}\right)}{\bar{m} \sigma(\rho+g)}=p_{K} \kappa_{X}, \quad \frac{L+\rho p_{K} \bar{\kappa}}{\sigma(\rho+g)}=p_{K} \bar{\kappa}
$$

These three expressions implicitly define the three equilibrating variables, $a_{D}, a_{X}$ and $g$.

\subsection{Discussion of the growth path}

The growth path in our model shares many similarities with the growth path of the canonical Grossman-Helpman product-innovation growth model that assumes homogenous varieties. The long-run growth path is characterised by a time-invariant division of labour between the production of capital goods (knowledge in our model) and consumption goods; the division is $\mathrm{L}_{\mathrm{I}}$ versus $\mathrm{L}-\mathrm{L}_{\mathrm{I}}$. The constant application of $\mathrm{L}_{\mathrm{I}}$ to knowledge creation yields a steadily rising mass of varieties due to the learning curve assumed in the I-sector, $\mathrm{c}[\cdot]$. Observe that ' $\mathrm{g}$ ' here is the equilibrating variable much as ' $n$ ' is in no-growth homogenous firm trade (HFT hereafter) models, like Melitz (2003). Because knowledge spillovers remove $\mathrm{n}$ from the calculation, it is the speed of innovation that ensures zero expected pure profit from variety introduction. The economic logic is that a faster

\footnotetext{
${ }^{9}$ From (6), the present value of all varieties, namely E/ $\sigma \gamma$, equals $\mathrm{p}_{\mathrm{K}} \bar{\kappa}$, since $\mathrm{p}_{\mathrm{K}}=\mathrm{nP}_{\mathrm{K}}$.
} 
growth of $\mathrm{n}$ drives down the expected benefit of introducing a new variety since it boosts the rate at which innovators expect the operating profit of a new variety to decline as per (3).

The constant flow of new varieties together with the time invariant employment of labour in the production of consumption goods means that consumption/production of each variety continuously declines at a rate of $g$. The representative consumer sees her real consumption, E/P, rise at:

$$
g_{C}=\frac{g}{\sigma-1}
$$

where $\mathrm{g}_{\mathrm{C}}$ is the growth rate of real consumption. ${ }^{10}$ In the working paper version of our paper (Baldwin and Robert-Nicoud, 2005), we proved that the laissez-faire mass of varieties and cut-off points along the steady-state growth path are socially optimal, but the laissez-faire growth rate is too low from the planner's perspective.

\section{GROWTH EFFECTS OF MARKET OPENNING}

Solving the third expression in (12):

$$
g=\frac{L / \sigma}{p_{K} \bar{\kappa}}-\frac{\rho(\sigma-1)}{\sigma}
$$

Since everything here is a parameter except $\mathrm{p}_{\mathrm{K}} \bar{\kappa}$, all growth effects of trade must come through the expected sunk cost of getting a new variety, i.e. the denominator of Tobin's q. Thus:

Result 1 : Closer international economic integration is pro-growth if and only if it lowers the expected sunk cost of developing a new, produced variety (namely, $p_{K} \bar{\kappa}$ ). This allows us to define two growth-effect channels: the $p_{K}$-channel and the $\bar{\kappa}$-channel.

\subsection{Pro- and anti-growth effects}

Anti-growth. As it turns out, the $\bar{\kappa}$-channel is unambiguously anti-growth since the expected sunk cost of getting a 'winner' rises with freer trade. Intuitively, freer trade makes it easier to export, so the threshold marginal cost for exporting, ax, rises. The increased competition from imports makes both markets more competitive and this lowers the common $a_{D}$ (the extra competition induces the least efficient D-type firms to cease production). From the definition of $\bar{\kappa}$ in (5), this means that the typical winner is more likely to be an X-type and a successful entry will require more tries before getting a winner; both factors raise $\bar{\kappa} \cdot{ }^{11}$ In short trade may be anti-growth since it raises the fixed knowledge-requirement of new varieties conditional on entry.

\footnotetext{
${ }^{10}$ This follows from the fact that the ideal CES price index is $\mathrm{P}=\left\{(\mathrm{n} \bar{m})^{1 /(1-\sigma)}\right\} /(1-1 / \sigma)$.

${ }^{11}$ See Melitz (2003) for proof with a general G; below we demonstrate this for a specific functional form.
} 
Pro-growth. Freer trade in goods and ideas may alter the price of new knowledge, $\mathrm{p}_{\mathrm{K}}$. We cannot be more precise without an explicit functional form for $c[w, \vec{a}, n]$, but two well-known economic mechanisms suggest that the $\mathrm{p}_{\mathrm{K}}$-channel will usually be pro-growth. One concerns the price-lowering impact of freer trade on goods prices and the indirect impact of this on $\mathrm{p}_{K}$ when the knowledge-producing sector uses intermediate inputs - 'lab equipment.' An entirely separate line of reasoning concerns international knowledge spillovers. If tighter integration makes the flow of ideas freer then we would expect learning in each nation to have a greater cost-lowering impact in both nations and this would show up in a lower $\mathrm{p}_{\mathrm{K}}$.

\subsection{Analytic solutions and microfoundations for I-sector technology}

Analysis up to this point has been conducted without resort to a functional form for G. Much of the subsequent analysis can also be conducted in this manner, but the reasoning is clearer with explicit solutions for $\mathrm{a}_{\mathrm{D}}, \mathrm{a}_{\mathrm{X}}$ and $\mathrm{g}$. We assume a Pareto distribution:

$$
G[a]=\left(a / a_{0}\right)^{k} \quad 0 \leq a \leq a_{0} \equiv 1
$$

where $\mathrm{k}$ and $\mathrm{a}_{0}$ are the 'shape' and 'scale' parameters, respectively. By choice of units, $\mathrm{a}_{0}$ is normalised to unity without loss of generality. With (15), we solve $\bar{m}$ and $\bar{\kappa}$, so (12) yields: ${ }^{12}$

$$
g=\frac{L / \sigma}{p_{K} \bar{\kappa}}-\frac{\rho(\sigma-1)}{\sigma}, \quad a_{D}=\left(\frac{(\beta-1) \kappa_{I}}{(1+\Omega) \kappa_{D}}\right)^{1 / k}, \quad a_{X}=\left(\frac{\Omega(\beta-1) \kappa_{I}}{(1+\Omega) \kappa_{X}}\right)^{1 / k}
$$

where $\mathrm{p}_{\mathrm{K}}=c[1, \vec{a}, 1], \bar{\kappa}=\beta \kappa_{D}(1+\Omega) /(\beta-1)$ and ${ }^{13}$

$$
\Omega \equiv \phi^{\beta} T^{1-\beta}, \quad T \equiv \kappa_{X} / \kappa_{D}, \quad \beta \equiv k /(\sigma-1)>1
$$

Omega as a measure of openness. $\Omega$ (a mnemonic for 'openness') is a Cobb-Douglas average of the two types of trade barriers in the HFT model, variable trade cost (as measured by freeness $\phi$ ) and fixed trade costs (as measured by the excessive beachhead cost facing imported varieties, namely $\left.\mathrm{T} \equiv \mathrm{F}_{\mathrm{X}} / \mathrm{F}_{\mathrm{D}}\right)$. $\Omega$ displays several convenient features. It combines the protective effects of fixed and variable trade costs, and it is bound between zero and unity with zero indicating autarky and unity indicating free trade.

\subsubsection{Microfoundations for the I-sector marginal cost function}

\footnotetext{
${ }^{12}$ Specifically, $\bar{m}=\beta\{(1+\Omega) /(\beta-1)\}^{1+\beta}\left(\kappa_{D} / \kappa_{I}\right)^{\beta}$.

${ }^{13}$ The restriction $\beta>1$ ensures the integrals converge.
} 
The strength of the $\mathrm{p}_{\mathrm{K}}$-channel depends upon $c[w, \vec{a}, 1]$. Five special cases are considered. ${ }^{14}$

Grossman-Helpman model. The canonical Grossman-Helpman product-innovation model assumes a learning curve where the marginal cost of creating knowledge falls as the I-sector's cumulative production, $\mathrm{n}$, rises. Specifically:

$$
c[w, \vec{a}, n]=\frac{w}{n+\lambda n^{*}} \quad \Rightarrow \quad p_{K} \bar{\kappa}=\frac{\beta \kappa_{D}(1+\Omega)}{(\beta-1)(1+\lambda)}
$$

where $0 \leq \lambda \leq 1$ (lambda is a mnemonic for 'learning') measures the international dimension of spillovers; this is for the Home nation, but the Foreign nation's is identical since $n=n *$ by symmetry. (The original Grossman-Helpman version considered the extremes of no and perfect spillovers, i.e. $\lambda=0$ and $\lambda=1$.) Many justifications of this intertemporal externality are possible. Romer (1990) rationalizes it by referring to the non-rival nature of knowledge. Grossman and Helpman (1991) assert that it reflects the impact of 'public knowledge' that is created automatically along with the private, patentable knowledge that leads to new varieties.

Coe-Helpman model. A variant of (17) makes $\lambda$ a function of trade flows by equating $\lambda$ to the fraction of foreign varieties that are imported, namely $\left(a_{X} / a_{D}\right)^{k}$, i.e.:

$$
\tilde{\lambda} \equiv\left(a_{X} / a_{D}\right)^{k} \quad \Rightarrow \quad p_{K} \bar{\kappa}=\frac{\beta \kappa_{D}(1+\Omega)}{(\beta-1)(1+\Omega / T)}
$$

where $\tilde{\lambda}$ replaces $\lambda$ in (17). Coe and Helpman (1995) provide empirical evidence that knowledge spillovers are related to trade flows; see Keller (2002) for a critique.

Efficiency-linked knowledge spillovers. Expression (17) assumes that I-sector learning is equal for all varieties (the impact on $\mathrm{p}_{\mathrm{K}}$ is the same for $\mathrm{X}$ - and D-types). An alternative is to assume that the extent of the spillovers is proportional to the average efficiency of the produced varieties, so the n's are weighted by the average marginal cost $\bar{m}$ and $\bar{m}^{*}$. Noting $\mathrm{n}=\mathrm{n}^{*}$ and $\bar{m}=\bar{m}^{*}$ :

$$
c[w, \vec{a}, n]=\frac{w}{\left(n \bar{m}+n^{*} \bar{m}^{*}\right) / 2} \quad \Rightarrow \quad p_{K} \bar{\kappa}=\frac{\left\{(\beta-1) \kappa_{I}\right\}^{\beta}}{(1+\Omega)^{\beta} \kappa_{D}^{\beta-1}}
$$

Reverse engineering. The three previous special cases treat I-sector learning as proportional to the number of varieties the sector has produced. Varieties, however, contain different units of knowledge depending upon their export status. The average number of knowledge units in a locally produced variety is $\bar{\kappa}$, as per (5), but it is higher for an imported variety, namely $\kappa_{D}+\kappa_{X}+\kappa_{I}$.

\footnotetext{
${ }^{14}$ We thank one referee for suggesting the second and third.
} 
Presuming that the local I-sector only learns from varieties that it can actually purchase (the idea being only these can be 'reverse engineered'), $c[w, \vec{a}, n]$ would be:

$$
c[w, \vec{a}, n]=\frac{w}{n \bar{\kappa}+\tilde{\lambda} n * \bar{\kappa}_{X}} \quad \Rightarrow \quad p_{K} \bar{\kappa}=\left(1+\frac{(\beta-1) \bar{\kappa}_{X} \Omega}{\beta T(1+\Omega)}\right)^{-1}
$$

where $\bar{\kappa}_{X}$ equals $\kappa_{D}+\kappa_{X}+\kappa_{I}$ and $\tilde{\lambda}$ is from (18); again $\mathrm{n}=\mathrm{n} *$.

Lab-equipment model. Another well-known product-innovation model, Rivera-Batiz and Romer (1991), supposes that knowledge is produced using the final good CES composite, so: ${ }^{15}$

$$
c[w, \vec{a}, n]=P^{\alpha} ; \quad P=(n \bar{m})^{\frac{1}{1-\sigma}}, \quad \alpha=\sigma-1 \quad \Rightarrow \quad p_{K} \bar{\kappa}=\kappa_{D}\left(\frac{\left.(\beta-1) \kappa_{I}\right)}{(1+\Omega) \kappa_{D}}\right)^{\beta}
$$

where $\mathrm{P}$ is the CES price index, and the restriction on $\alpha$ is implied by our homogeneity assumption on $c[w, \vec{a}, n]$. This provides microfoundations for a connection between the cost of goods and the productivity of the knowledge creating sector. ${ }^{16}$ Plainly, these five special cases could be mixed and matched to create a wide range of possibilities.

\subsection{Autarky to Free Trade liberalisation}

The product $\bar{\kappa} p_{K}$ is the pivot for growth effects, as per Result 1. Having worked out the analytic solutions for $\bar{\kappa} p_{K}$ in the five cases, evaluation of the growth effects of freer trade is straightforward. We start with a base-case comparison of two conceptual extremes, complete autarky and complete integration. When nations are autarkic in terms of the flow of goods and ideas, $\Omega=\lambda=1 / \mathrm{T}=0$; when they are fully integrated $\Omega=\lambda=\mathrm{T}=1$.

The Grossman-Helpman and Coe-Helpman models display the same growth rate in the two conceptual extremes. Intuitively, this is because the shift to full goods-market openness $(\Omega=0$ to $\Omega=1$ ) increases the amount of knowledge per variety, $\bar{\kappa}$, by exactly the same amount that the increase in ideas-openness $(\lambda=0$ to $\lambda=1)$ lowers the per-unit price of knowledge. This result does not hold for the other models of innovation, the efficiency-linked, reverse-engineering and labequipment models. In these models zero-to-full integration is pro-growth. The stark contrast in results is due to the connection between manufacturing-sector average productivity and innovationsector productivity. In the Grossman-Helpman and Coe-Helpman models there is no direct connection while there is in the other three models, so the well-known productivity enhancing

\footnotetext{
${ }^{15}$ The same 'output composite' can either be consumed or invested as in traditional growth models.
} 
effects of liberalisation in the HFT models (so-called shifting and sorting effects) stimulate innovation in the latter but not the former. Next, consider marginal changes in integration.

\subsection{The growth effect of freer trade in goods and ideas}

The term $\bar{\kappa} p_{K}$ is the pivot for growth effects, but observe that all ambiguity of growth effects stems from the $\mathrm{p}_{\mathrm{K}}$-channel. In all five cases, $d \bar{\kappa} / d \phi$ equals $\left\{\beta \kappa_{\mathrm{D}} /(\beta-1)\right\}(\mathrm{d} \Omega / \mathrm{d} \phi)>0$, so the $\bar{\kappa}$-channel is unambiguously anti-growth. If the overall effect is positive, it must be that the $\mathrm{p}_{\mathrm{K}}$-channel is progrowth and sufficiently strong to overwhelm the negative $\bar{\kappa}$-channel effect. We consider freer trade with respect to variable trade costs (i.e. $d \phi>0$ ), with respect to fixed trade costs (i.e. $d T<0$ ), and with respect to trade in ideas, (i.e. $\mathrm{d} \lambda>0)$.

Lower variable trade-costs. Reducing iceberg trade costs tends to slow growth in two cases, speeding it in three cases. Given Result $1, \Omega \equiv \phi^{\beta} \mathrm{T}^{1-\beta}$ and the simple analytic solutions in (17)-(21), the proofs are by inspection of the relevant expression for $p_{K} \bar{\kappa}$.

- Under the expression (17) knowledge-creating technology (Grossman-Helpman), d $\phi>0$ has no impact on $\mathrm{p}_{\mathrm{K}}$, so the $\mathrm{p}_{\mathrm{K}}$-channel does nothing to offset the negative $\bar{\kappa}$-channel effect. The overall impact is therefore anti-growth (our working paper version, Baldwin and Robert-Nicoud 2005, discusses this case at length).

- Under the expression (18) knowledge-creating technology (Coe-Helpman), the $\mathrm{p}_{\mathrm{K}}$-channel is positive, but it is not sufficiently large to offset the negative $\bar{\kappa}$-channel effect unless $\mathrm{T}=1$ in which case the net growth effect is zero (NB: $\mathrm{T}=1$ implies the beachhead cost is the same for a local and imported variety).

- Under the expression (19) knowledge-creating technology (efficiency-linked spillovers), the $\mathrm{p}_{\mathrm{K}}$-channel is positive. It is also strong enough to overcome the anti-growth $\bar{\kappa}$-channel. Formally, the result can be seen by inspection of (19). Intuitively, the pro-growth $\mathrm{p}_{\mathrm{K}}$-channel is driven by the productivity enhancing impact of freer trade, which is in turn driven by a selection effect (weaker firms are eliminated and more firms export) and a share-shifting effect (the market shares of the most efficient firms rise while those of inefficient firms falls). The anti-growth effect, however, is driven by the selection effect alone (i.e. $d\left(a_{X}\right)>0$ and $\left.d\left(a_{D}\right)<0\right)$ and so it is weaker.

\footnotetext{
${ }^{16}$ In this case, the expression for $\mathrm{E}$ in operating profits is just $\mathrm{Y}$ since both $\mathrm{E}$ and $\mathrm{S}$ are spent on goods.
} 
- $\quad$ Under the expression (20) knowledge-creating technology (reverse engineering), the $\mathrm{p}_{\mathrm{K}^{-}}$ channel is positive. It dominates the anti-growth $\bar{\kappa}$-channel, so the overall effect is pro-growth as inspection of (20) reveals. Intuitively, we can think of this as the Coe-Helpman model with an extra fillip for international knowledge spillovers. This extra fillip is due to the fact that imported varieties systematically 'embody' more knowledge since they have been adapted to meet the beachhead costs in both markets, while some of the locally-produced varieties embody only $\kappa_{\mathrm{I}}$ and $\kappa_{\mathrm{D}}$ units of knowledge. Notice that this extra effect is strong enough to overcome the anti-growth $\bar{\kappa}$-channel even when $\mathrm{T}$ is very large but finite.

- Under the expression (21) knowledge-creating technology (lab-equipment), the $\mathrm{p}_{\mathrm{K}}$-channel is positive and strong enough to overcome the fact that freer trade raises the expected sunk cost of getting a 'winner.' As in the efficiency-linked-spillovers model, the result is due to the powerful, pro-efficiency impact of freer trade in the HFT model.

Lower fixed trade-costs. Reducing $F_{X}$ to the level of $F_{D}$ (i.e. $d T<0$ ) has qualitatively identical effects on growth as $d \phi>0$ in three of the five cases since $T$ and $\phi$ appear bundled in $\Omega$. These are the cases where the degree of international spillovers, $\lambda$. is exogenous, viz. (17), (19) and (21). When the international spillovers parameter $\lambda$ is linked to the fraction of foreign varieties that are traded, then $\mathrm{T}$ has an independent effect on growth since this fraction is a function of $\mathrm{T}$, i.e. from (16) and the definition of $\tilde{\lambda}$, we have $\tilde{\lambda}=\Omega / T$. It is easy to show that taking account of the T inside $\Omega$ and the explicit T in the models where $\lambda$ is endogenous, i.e. (18) and (20), lower fixed barriers to trade is always pro-growth. The intuition is obvious. Since lower T encourages spillovers by increasing the fraction of traded varieties, it tends to be pro-growth and this only adds to the progrowth effect from $\mathrm{d} \Omega>0$.

Higher knowledge spillovers. It is plain that raising the exogenous $\lambda$ in isolation is pro-growth since it lowers the expected cost of getting a 'winner' without any direct impact on the reward to getting a 'winner.' In the Grossman-Helpman model, openness to ideas, $\lambda$, opposes openness to goods, $\Omega$, such that they cancel if they are equal, viz. $\lambda=\Omega$; in this case, greater openness has no impact on growth.

\subsection{The Role of Heterogeneity and beachhead costs}


The role of heterogeneity and beachhead effects in trade and growth links are quite obvious. ${ }^{17}$ If the beachhead costs are eliminated, integration has no impact on the range of varieties and so the $\bar{\kappa}$-channel is eliminated; it turns $\tilde{\lambda}, \bar{m}, \bar{\kappa}$ and $\bar{\kappa}_{X}$ into parameters. It also eliminates most of the effects on the $\mathrm{p}_{\mathrm{K}}$-channel. Changes in the exogenous learning spillovers (as measured by $\lambda$ ) still effect growth, and the price lowering impact of integration feeds directly into $\mathrm{p}_{\mathrm{K}}$ in the labequipment model. Note that when $\mathrm{T}=\mathrm{F}_{\mathrm{X}} / \mathrm{F}_{\mathrm{D}}=1$ the growth effects of freer-trade (in the traditional iceberg sense) are unchanged, except for the Coe-Helpman model. In this case, T=1 implies the anti-growth $\bar{\kappa}$-channel exactly offsets the pro-growth $\mathrm{p}_{\mathrm{K}}$-channel.

\subsection{Static versus dynamic productivity effects}

A major finding of heterogeneous-firms trade theory is that trade openness can raise productivity via selection and share-shifting effects (Melitz 2003). Defining 'measured productivity' as the ratio of real manufacture output to manufacturing labour input, we note that openness also boosts productivity in our model since greater openness lowers the ideal CES price index. However, in cases such as (17), openness slows the rate at which the price index falls and so slows the rate of productivity improvement. This implies that there may be tension between the static and dynamic productivity effects of trade in an HFT model.

\section{WeLfare}

Most of the welfare issues in our model are simple. The present value of utility on the equilibrium growth path at time $\mathrm{t}=0$ is $\mathrm{U}_{0}=\mathrm{E} / \mathrm{P}_{0}(\rho+\mathrm{g})$. Using the permanent income expression for $\mathrm{E}, \mathrm{P}$ from (21), and the analytic solution for $\bar{m}$, we have:

$$
U_{0}=\left(\frac{\sigma}{p_{K} \bar{\kappa}}\right)\left(\beta\left(\frac{1+\Omega}{\beta-1}\right)^{1+\beta}\left(\frac{\kappa_{D}}{\kappa_{I}}\right)^{\beta}\right)^{1 /(\sigma-1)}
$$

The first term in parentheses reflects the dynamic welfare aspects, i.e. $U_{0}=E /(\rho+g)$, and the second captures the static aspects, i.e. $1 / \mathrm{P}_{0}$. Plainly greater openness (i.e. $\mathrm{d} \Omega>0$ ) always produces positive static effects. The sign of the dynamic normative effects of greater openness balance on the same fulcrum as did the positive effects, namely $\mathrm{p}_{\mathrm{K}} \bar{\kappa}$.

Indeed, the decentralised growth rate $\mathrm{g}$ is suboptimal from a welfare perspective because innovators do not internalise the positive dynamic (learning) externalities they exert on future innovations (see Grossman and Helpman 1991 and Baldwin and Robert-Nicoud 2005). As a result, any policy that

\footnotetext{
${ }^{17}$ See our working paper version for the mathematical details.
} 
raises growth reduces the gap between the market growth rate and the desirable one is welfare improving in a dynamic sense. To summarise:

Result 2: The static welfare effect of greater openness is always positive; since laissez-faire growth is sub-optimal from the social-welfare perspective, the dynamic welfare effect is positive if and only if greater openness raises the growth rate. Given Result $\mathbf{1}$, this means that a sufficient condition for greater openness to be welfare enhancing is that greater openness lowers the expected cost of a new produced variety, namely $p_{K} \bar{\kappa}$.

Thus for 3 of the 5 special cases for I-sector technology, namely (19), (20) and (21, we can say the welfare effects are unambiguously positive, given the analysis in Section 4. Welfare ambiguity arises when openness is anti-growth since it creates a tension between welfare-enhancing static effects and welfare-worsening dynamic effects. In the Grossman-Helpman case in which openness is the most strongly anti-growth:

$$
U_{0}=\left(\frac{\sigma(1+\lambda)}{\beta \kappa_{D}}\right)\left(\beta\left(\frac{1+\Omega}{\beta-1}\right)^{2-\sigma+\frac{k}{\sigma-1}}\left(\frac{\kappa_{D}}{\kappa_{I}}\right)^{\frac{k}{\sigma-1}}\right)^{1 /(\sigma-1)}
$$

By inspection, this is unambiguously increasing in openness as measured by $\lambda$ and as measured by $\Omega$ as well only if $\sigma$ is small enough; in such cases, openness raise welfare despite the negative impact on growth.

\section{CONCLUDING REMARKS}

This paper explores the growth effects of trade when firms are heterogeneous and face sunk marketentry costs. Our findings can be viewed as speaking to the trade and growth literature on one hand, and the new-new trade theory on the other. As far as trade and growth is concerned, our main finding - that freer trade has an ambiguous impact on growth - contrasts with most findings in the homogeneous-firms endogenous growth literature where positive effects are the standard result; this ambiguous finding squares better with the empirical evidence on the effects of trade openness on growth (see Berg and Krueger, 2003, for a survey). Specifically, our model stresses the need for empirical researchers to better investigate the link between trade and the dissemination of knowledge, in particular its impact on the efficiency of the innovation sector. As far as the new-new trade theory is concerned, our main finding is that there is tension between static and dynamic productivity effects. Although freer trade improves industry productivity in a level sense, it may harm it in a growth sense, at least when ideal price indices are used to measure real output. 
One line of research that would be interesting would be to explore the impact of unilateral trade liberalisation. However, this analysis becomes very involved, so we leave this for future research.

\section{REFERENCES}

Aw, B., Chung, S. and Roberts, M., 2000, 'Productivity and Turnover in the Export Market: Micro Evidence from Taiwan and South Korea', World Bank Economic Review 14, 65-90.

Baldwin, Richard E. (1988), 'Hysteresis in Import Prices: The Beachhead Effect, American Economic Review, 78(4), 773-785.

Baldwin, Richard E. and Paul Krugman (1989), 'Persistent Trade Effects of Large Exchange Rate Shocks,' Quarterly Journal of Economics 419, 635-654.

Baldwin, Richard E. and Frédéric Robert-Nicoud (2005). "Trade and growth with heterogenous firms," CEPR Discussion Paper 4965.

Baldwin, Richard E. and Rikard Forslid (2000). "Trade liberalisation and endogenous growth: A $q$ theory approach ", Journal of International Economics 50(2), 497-517.

Baldwin, Richard E. and Rikard Forslid (2004). "Trade liberalisation with heterogenous firms," CEPR Discussion Paper 4635.

Berg, Andrew and Ann O. Krueger (2003). Trade, growth, and poverty: A selective survey. IMF working paper no. WP/03/30.

Bernard A. and Jensen B, 1995, 'Exporters, Jobs and Wages in U.S. Manufacturing, 1976-1987' Brookings Papers on Economic Activity, Microeconomics, 67-119

Bernard A. and Jensen B., 2001, 'Why Some Firms Export', NBER working paper 8349

Bernard A. and Jensen, B., 1999b, 'Exporting and Productivity: Importance of Reallocation', NBER working paper 7135 .

Bernard, A. and Jensen, B., 1999a, 'Exceptional Exporter Performance: Cause, Effect, or Both?' Journal of International Economics 47, 1-26

Bernard, A.B., J. Eaton, J.B. Jensen and S. Kortum (2003) "Plants and Productivity in International Trade", American Economic Review, Vol. 93, No. 4, September, 1268-1290.

Bernard, Andrew B., Stephen Redding, Peter K. Schott (2004), “Comparative Advantage and Heterogeneous Firms," NBER Working Paper No. 10668. 
Bernard, Andrew, Jonathan Eaton, J. Bradford Jensen, and Peter Schott (2003). "Falling Trade Costs, Heterogeneous Firms and Industry Dynamics", mimeo, Tuck School.

Chaney, Thomas (2005). “The Dynamic Impact of Trade Opening: Productivity Overshooting with Heterogeneous Firms.” MIT mimeo.

Clerides S., Lach, S. and Tybout, J., 1998, 'Is Learning by Exporting Important? Micro-Dynamic Evidence from Colombia, Mexico, and Morocco', Quarterly Journal of Economics, 133, 903- 904

Coe, David T. \& Helpman, Elhanan, 1995. "International R\&D spillovers," European Economic Review, Elsevier, vol. 39(5), pages 859-887.

Demidovay, Svetlana (2005). "Productivity Improvements and Falling Trade Costs: Boon or Bane?", The Pennsylvania State University mimeo.

Dinopoulos, E. and Segerstrom P, (1999b), “A Schumpeterian Model of Protection and Relative Wages", American Economic Review, 89, 450-473.

Dinopoulos, E. and Segerstrom P., (1999a), "The Dynamic Effects of Contingent Tariffs”, Journal of International Economics, 47, 191-222.

Eaton, Jonathan and Samuel Kortum (2002). "Technology, Geography and Trade,” Econometrica, 70, 5, pp 1741-1780.

Eaton, Jonathan and Samuel Kortum (2002). “Technology, trade, and growth: A unified framework," European Economic Review, vol. 45(4-6), pages 742-755.

Eaton, Jonathan, Samuel Kortum, and Francis Kramarz (2004), "Dissecting Trade: Firms, Industries, and Export Destinations", American Economic Review Papers and Proceedings, 94, 2004, 150-154.

Grossman, G.M. and Helpman, E., 1989. "Trade; Innovation; and Growth," Papers 154, Princeton, Woodrow Wilson School - Public and International Affairs.

Grossman, Gene and Elhanan Helpman. (1991). Innovation and Growth in the World Economy. Cambridge, MA: MIT Press.

Grubel, Herbert G., P.J. Lloyd (1975) Intra-Industry Trade: The Theory and Measurement of International Trade in Differentiated Products (London, Macmillan).

Helpman, Elhanan and Paul Krugman (1985), Market structure and Trade, MIT Press. 
Helpman, Elhanan, Marc Melitz and Stephen Yeaple (2004). "Export versus FDI with heterogeneous firms," American Economic Review, 94, 1, pp. 300-317.

Hopenhayn, Hugo (1992a). Entry, Exit, and Firm Dynamics in Long Run Equilibrium. Econometrica 60:1127-1150.

Hopenhayn, Hugo (1992b). Exit, Selection, and the Value of Firms, Journal of Economic Dynamics and Control 16:621-653.

Keller W. (2002). "Trade and the transmission of technology," Journal of Economic Growth 7, 524.

Keller, W. (2004). 'International technology diffusion,' forthcoming Journal of Economic Literature.

Luttmer, Erzo G.J. (2005a). "Growth and the Size Distribution of Firms.” University of Minnesota mimeo.

Luttmer, Erzo G.J. (2005b). "The Size Distribution of Firms in an Economy with Fixed and Entry Costs.” Minnesota Fed Working Paper 633.

Melitz, M. (2003). "The impact of trade on intraindustry reallocations and aggregate industry productivity,” Econometrica, 71, pp 1695-1725.

Melitz, Marc and Gianmarco Ottaviano (2003), "Market Size, Trade and Productivity”, mimeo.

Rivera-Batiz, L. and P. Romer, 1991a, Economic integration and endogenous growth, Quarterly Journal of Economics 106, 531-555.

Rivera-Batiz, L. and P. Romer, 1991b, International trade with endogenous technological change", European Economic Review 35, 715-721.

Romer, P., 1986, Increasing returns and long-run growth, Journal of Political Economy 94, 10021037.

Romer, P., 1990, Endogenous technological change, Journal of Political Economy 98, 71-102.

Tybout, J., 2003, Plant- and Firm-level Evidence on "New" Trade Theories', in E. K. Choi and J. Harrigan (eds) Handbook of International Trade Blackwell, Oxford.

Yeaple, S. (2005), Firm Heterogeneity, International Trade, and Wages, Journal of International Economics, 65(1), pp 1-20. 


\section{Guide to Calculations by Footnote: "Trade and growth with heterogeneous firms"}

(not for publication, will be posted on the web)

Richard E. Baldwin and Frédéric Robert-Nicoud

2. The constant operating profit mark-up follows directly from the standard Dixit-Stiglitz result of constant cost-price mark-up; for example, rearranging the first order condition for local sales, $\mathrm{p}(1-1 / \sigma)=a$ we get that operating profit earned on local sales is $(\mathrm{p}-\mathrm{a}) \mathrm{c}=\mathrm{pc} / \sigma$, where $\mathrm{c}$ is local sales.

5. The direct approach to formulating the condition for zero-expected-profit-from-innovation is to calculate the expected benefit net of market entry costs, i.e. $\int_{0}^{a_{D}}\left\{a^{1-\sigma}(E / \sigma \bar{m} \eta)-F_{D}\right\} d G[a]+\phi \int_{0}^{a_{X}}\left\{a^{1-\sigma}(E / \sigma \bar{m} m)-F_{X}\right\} d G[a]$, which simplifies to $(\mathrm{E} / \sigma \bar{m} m)\left(\mathrm{A}\left[\mathrm{a}_{\mathrm{D}}\right]+\phi \mathrm{A}\left[\mathrm{a}_{\mathrm{X}}\right]\right)$ minus $\left(\mathrm{G}\left[\mathrm{a}_{\mathrm{D}}\right] \mathrm{F}_{\mathrm{D}}+\mathrm{G}\left[\mathrm{a}_{\mathrm{X}}\right] \mathrm{F}_{\mathrm{X}}\right)$, where $A[x] \equiv \int_{0}^{x} a^{1-\sigma} d G[a]$. Notice, however, that (3) implies $\mathrm{G}\left[\mathrm{a}_{\mathrm{D}}\right]=\left(\mathrm{A}\left[\mathrm{a}_{\mathrm{D}}\right]+\phi \mathrm{A}\left[\mathrm{a}_{\mathrm{X}}\right]\right) / \bar{m}$, the benefit less market-entry costs is $G\left[a_{D}\right](E / n \sigma \gamma)-G\left[a_{D}\right] F_{D}-G\left[a_{X}\right] F_{X}$. This is set equal to $F_{I}$ in the direct approach. Dividing this through by $G\left[a_{D}\right]$ validates our indirect approach in (6). We adopt the indirect approach since it allows us to deal more clearly with growth and corresponds more closely to Tobin's insightful approach to characterising investment in a general equilibrium setting. It also allows a direct comparison with standard endogenous growth models (which do not have market-entry costs) and it facilitates analysis of growth effects by concentrating the impact of openness and parameter changes in the expected cost of getting a winner.

6. See Baldwin and Forslid (2000), Proposition 1 for a general proof that the direct impact on Tobin's q is a sufficient statistic for growth effects in this sort of model. Intuitively, this is obvious since anything that raise Tobin's q encourages more investment and this, in an endogenous growth model, results in faster growth. The faster growth, in turn, returns Tobin's q back to its steady state value of unity. All the variables in the numerator of Tobin's q are either endogenous (e.g. E) or are parameters unrelated to trade liberalisation.

7. Formally, income is $\mathrm{L}+\mathrm{rW}$, where $\mathrm{W}$ is wealth, $\mathrm{r}$ is the rate of return, and $\dot{W}=\mathrm{L}+\mathrm{rW}-\mathrm{E}$ describes wealth accumulation. The Hamiltonian is $\mathrm{e}^{-\mathrm{pt}} \ln (\mathrm{E} / \mathrm{P})+\omega(\mathrm{L}+\mathrm{rW}-\mathrm{E})$ and $\mathrm{r}$ and the path of $\mathrm{P}$ is 
exogenous to the consumer/saver. The necessary conditions are $\mathrm{e}^{-\mathrm{pt}} / \mathrm{E}=\omega$ and $-\omega \mathrm{r}=\dot{\omega}$ plus a transversality condition. Manipulation involving the time derivative of the first condition and substitution of the second condition yields the Euler equation.

8. The two differential equations are:

$$
\dot{E} / E=r-\rho, \quad \frac{\dot{n}}{n}=\frac{L_{I}}{p_{K} \bar{\kappa}}
$$

Doing a standard change-of-variables transformation, we take $\mathrm{L}_{\mathrm{I}}$ and $g \equiv \dot{n} / n$ as the state variables and, using (10), the system becomes:

$$
\frac{-\dot{L}_{I}}{L-L_{I}}=r-\rho, \quad \frac{\dot{n}}{n}=\frac{L_{I}}{p_{K} \bar{\kappa}}
$$

As usual, changing state variables has no impact on the system dynamics. As is well know from decades of growth models, this system is saddle path stable. Also, as in most endogenous growth models, there is no transitional dynamics since the saddle path is a point, namely the steady state equilibrium. The system jumps immediately to the steady state since otherwise the system would violate the transversality conditions. All these assertions are proved at great length and generality in Grossman and Helpman (1991) and other textbooks on growth. The exact proof in this case can be found in Baldwin and Forslid (2000) which uses Tobin's q approach to evaluate the growth effects of trade in a homogenous goods model.

Our use of 'state variable' is somewhat unconventional in the standard terminology of economic dynamics (where state variable means a non-jumper and co-state and control variables are jumpers). Mathematically speaking, the state vector is the set of variables defines the state of the system fully. This includes variables that can jump or only move smoothly. Thus what economists usually call control variables, co-state variable and state variables are, mathematically speaking, all state variables. After all, one needs to know them all in order to fully characterise the state of the system. For example, in the simple differential equation $\dot{x}=\rho x \mathrm{x}$ is the state variable whether it is a jumper or not. The trick of taking $\mathrm{L}$ as numeraire and $\mathrm{L}_{\mathrm{I}}$ as a state variable opens the door to the intuitive simplification of working with the static economy representation of the dynamic path, i.e. focusing on the share of primary resources devoted to creation of new 'capital' and the creation of consumption goods. Anything that raises the share of L devoted to capital (i.e. knowledge in our model) creation is pro-growth. 


\section{CENTRE FOR ECONOMIC PERFORMANCE Recent Discussion Papers}

726 Gustavo Crespi Chiara Criscuolo Jonathan Haskel

725 Giovanni Olivei Silvana Tenreyro

724 Ghazala Yasmeen Azmat

723 Sharon Belenzon

722 Daron Acemoglu Philippe Aghion Claire Lelarge John Van Reenen Fabrizio Zillibotti

721 Sharon Belenzon

720 Rafael Gomez Konstantinos Tzioumis

719 Ralph Ossa

718 Nick Bloom

717 Holger Breinlich

716 Nick Bloom John Van Reenen

715 Mirko Draca Stephen Machin John Van Reenen
Productivity, Exporting and the Learning-byExporting Hypothesis: Direct Evidence from UK Firms

The Timing of Monetary Policy Shocks

The Incidence of an Earned Income Tax Credit: Evaluating the Impact on Wages in the UK

Basic Research and Sequential Innovation

Technology, Information and the Decentralization of the Firm

Knowledge Flow and Sequential Innovation: Implications for Technology Diffusion, R\&D and Market Value

What Do Unions Do to CEO Compensation?

A Gold Rush Theory of Economic Development

The Impact of Uncertainty Shocks: Firm Level Estimation and a 9/11 Simulation

Trade Liberalization and Industrial Restructuring through Mergers and Acquisitions

Measuring and Explaining Management Practices Across Firms and Countries

Minimum Wages and Firm Profitability 
714 Matteo Bugamelli

Francisco Paternò

713 Alex Bryson

712 Marco Manacorda

Carolina Sanchez-Paramo

Norbert Schady

711 Claudia Olivetti

Barbara Petrongolo

710 Hilary Steedman

709 Florence Kondylis

708 David Metcalf

Jianwei Li

707 Richard Walker

706 Miklós Koren

Silvana Tenreyro

705 Andy Charlwood

704 Michael W. L. Elsby

703 David Marsden

Richard Belfield

702 John Van Reenen
Do Workers' Remittances Reduce the Probability of Current Account Reversals?

Union Free-Riding in Britain and New Zealand

Changes in Returns to Education in Latin America: the Role of Demand and Supply of Skills

Unequal Pay or Unequal Employment? A CrossCountry Analysis of Gender Gaps

Apprenticeship in Europe: 'Fading' or Flourishing?

Agicultural Returns and Conflict: Quasi-Experimental Evidence from a Policy Intervention Programme in Rwanda

Chinese Unions: Nugatory or Transforming? An Alice Analysis

Superstars and Renaissance Men: Specialization, Market Size and the Income Distribution

Volatility and Development

The De-Collectivisation of Pay Setting in Britain 1990-1998: Incidence, Determinants and Impact

Evaluating the Economic Significance of Downward Nominal Wage Rigidity

Performance Pay for Teachers Linking Individual and Organisational Level Targets

The Growth of Network Computing: Quality Adjusted Price Changes for Network Servers

The Centre for Economic Performance Publications Unit Tel 02079557673 Fax 02079557595 Email info@cep.lse.ac.uk Web site http://cep.lse.ac.uk 